\title{
Utilization of Terrestrial Laser Scanning Data in Building Information Modelling (BIM) for Fire Disaster Evacuation Simulation
}

\author{
Abdi Sukmono*, Farhan Ardianzaf Putra, Nurhadi Bashit, Arief Laila Nugraha \\ Department of Geodetic Engineering, Diponegoro University, Indonesia
}

Received August 20, 2021; Revised September 29, 2021; Accepted October 28, 2021

\section{Cite This Paper in the following Citation Styles}

(a): [1] Abdi Sukmono, Farhan Ardianzaf Putra, Nurhadi Bashit, Arief Laila Nugraha, "Utilization of Terrestrial Laser Scanning Data in Building Information Modelling (BIM) for Fire Disaster Evacuation Simulation," Civil Engineering and Architecture, Vol. 9, No. 7, pp. 2129-2139, 2021. DOI: 10.13189/cea.2021.090702.

(b): Abdi Sukmono, Farhan Ardianzaf Putra, Nurhadi Bashit, Arief Laila Nugraha (2021). Utilization of Terrestrial Laser Scanning Data in Building Information Modelling (BIM) for Fire Disaster Evacuation Simulation. Civil Engineering and Architecture, 9(7), 2129-2139. DOI: 10.13189/cea.2021.090702.

Copyright $@ 2021$ by authors, all rights reserved. Authors agree that this article remains permanently open access under the terms of the Creative Commons Attribution License 4.0 International License

\begin{abstract}
The development of digital building modeling technology for documentation and spatial planning is growing rapidly. Along with the development of these technologies, the urgency concerning the level of accuracy in the measurement is also increasing. One of the technologies currently being developed to address the urgency is the creation of three-dimensional objects using the Terrestrial Laser Scanner (TLS). Three-dimensional (3D) imaging sensors, such as TLS, can be used to create a Building Information Model (BIM) of the condition of buildings and other facilities in the field. However, quality control needs to be carried out to ensure that the model accurately describes conditions in the field. Therefore, this study was conducted to determine the level of accuracy of the results of the BIM made by utilizing the TLS. In this study, researchers applied a deviation analysis method. This method produced an area with a significant difference between the point cloud data and the reconstructed model. The BIM went through a virtual disaster evacuation simulation process by utilizing the $\mathrm{A}^{*}$ search algorithm. The evaluation results of BIM deviation to the average point cloud were dominated by green results. This indicated that the deviation of the distance between the point cloud and the BIM data ranged from 0 to $2 \mathrm{~mm}$. The results of the test of accuracy in the field using a rolling meter showed that the RMSE value of the difference between the distance of the roll meter and the BIM was $0.0139 \mathrm{~m}$ with an average distance difference of $0.0102 \mathrm{~m}$.
\end{abstract}

The results of the creation of the evacuation route showed that the maximum distance of the evacuation route in the building was $21.251 \mathrm{~m}$ on the ground floor, $17.290 \mathrm{~m}$ on the 1st floor, $17.718 \mathrm{~m}$ on the 2nd floor, and $17.851 \mathrm{~m}$ on the 3rd floor. From the results of the simulation, the disaster evacuation took 89.8 seconds with an average evacuation process of 44 seconds. The length of the path has been in line with the applicable regulations, in which according to Indonesia's Minister of Public Works and Housing Regulation No. 26/2008, the maximum length of the path in educational residential buildings is $62 \mathrm{~m}$.

Keywords Deviation Analysis, BIM, Point Cloud, TLS

\section{Introduction}

Technological developments of building construction in recent years have developed rapidly. One of the innovations is the three-dimensional modeling of buildings. Technological advances allow the creation of detailed three-dimensional models to represent building conditions like the original conditions in the field.

The Building Information Model (BIM) is a digital database of $3 \mathrm{D}$ objects that have an orientation on a building [1]. Over the past ten years, the use of BIM has 
increased tremendously and is proving to be one of the greatest revolutions in the construction industry. Currently, the BIM industry is still focused on new buildings. However, there is an important movement from the research and laser scanning industry towards BIM (scan-to-BIM) for existing buildings, including cultural heritage buildings [2].

In the development of 3D modeling technology with existing building cases, point clouds are often used as the main data source for digital reconstruction. In the scan-to-BIM method, the processed point cloud is imported into commercial BIM software and used as a base during manual modeling. This process is generally considered to be inefficient, inaccurate, and error-prone [3]. The common errors include unknown materials, hidden internal structure elements, invisible elements, object history, conflicting sources, and potential geometric differences between the BIM and the actual building.

Currently, the scan-to-BIM process in the construction industry is still mostly manual or sometimes semi-automated using BIM software plugins for point cloud modeling. However, three scan-to-BIM approaches that may be applied do not have a clear method for assessing the geometric quality of BIM according to point clouds. A more standardized method for assessing the scan-to-BIM accuracy is the deviation analysis method [1]. The main idea of the deviation analysis method is that errors in BIM can be detected by analyzing the pattern in the difference between the TLS point cloud and the modeled BIM. In general, the BIM should be compatible with point cloud data and the difference (deviation) between the two types of data should not be too large. Areas with large deviations are potential problems [4].

Building Information Modeling (BIM) can be used as the basis for evacuation safety analysis data with minimum and safe costs [5]. This technology allows the development stage to be carried out more quickly, accurately, effectively, and efficiently as needed during the planning, design, construction, and operations phases. The creation of the BIM is carried out by applying the Close-Range Photogrammetry (CRP) method using a Terrestrial Laser Scanner (TLS). The BIM that has been created is then analyzed for evacuation routes using the A* search algorithm. This algorithm is widely used in video games because it is "heuristic" so that it can find the best solution for a problem. This algorithm works by prioritizing paths that appear to lead closer to the goal [6].

\section{Materials and Methods}

\subsection{Overview of Research Location}

In this study, the subject of research is the New Dean's Building of the Faculty of Engineering, Diponegoro University, Semarang. Geographically, this building is located at $7^{\circ} 3^{\prime} 5.326^{\prime \prime} \mathrm{S}$ and $110^{\circ} 26^{\prime} 24.373^{\prime \prime} \mathrm{E}$ and it is showed in Figure 1.

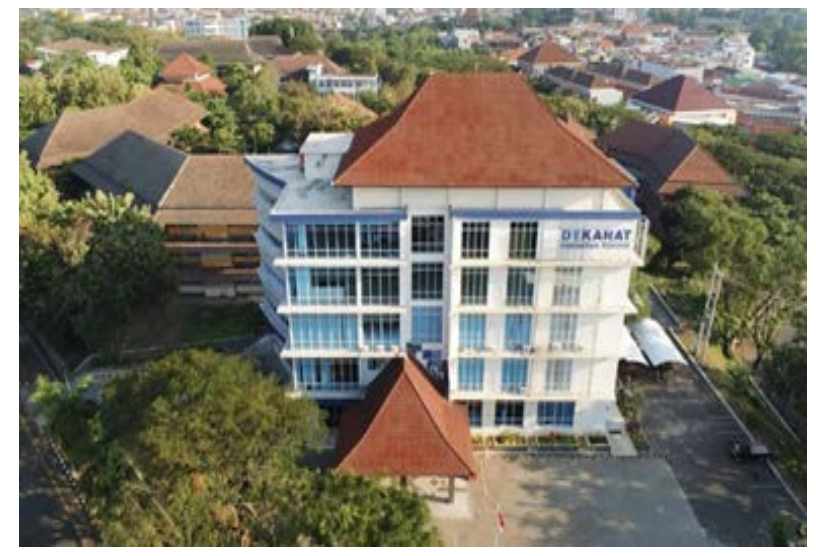

Figure 1. The New Dean's Building of the Faculty of Engineering, Diponegoro University

This building began construction in 2009 and was completed in 2016. This building replaces the old dean's building which was converted into classrooms, administrative offices, and the offices of the Head of Department. In this study, the researchers limit the scope of the research to only focus on measuring the ground floor to the 4th floor due to the limitations of existing tools.

\subsection{Methods}

This study examines the use of Terrestrial Laser Scanning data in the making of Building Information Models (BIM) for fire disaster evacuation simulations. The steps taken in this study are described in the flow chart in Figure 2 below: 


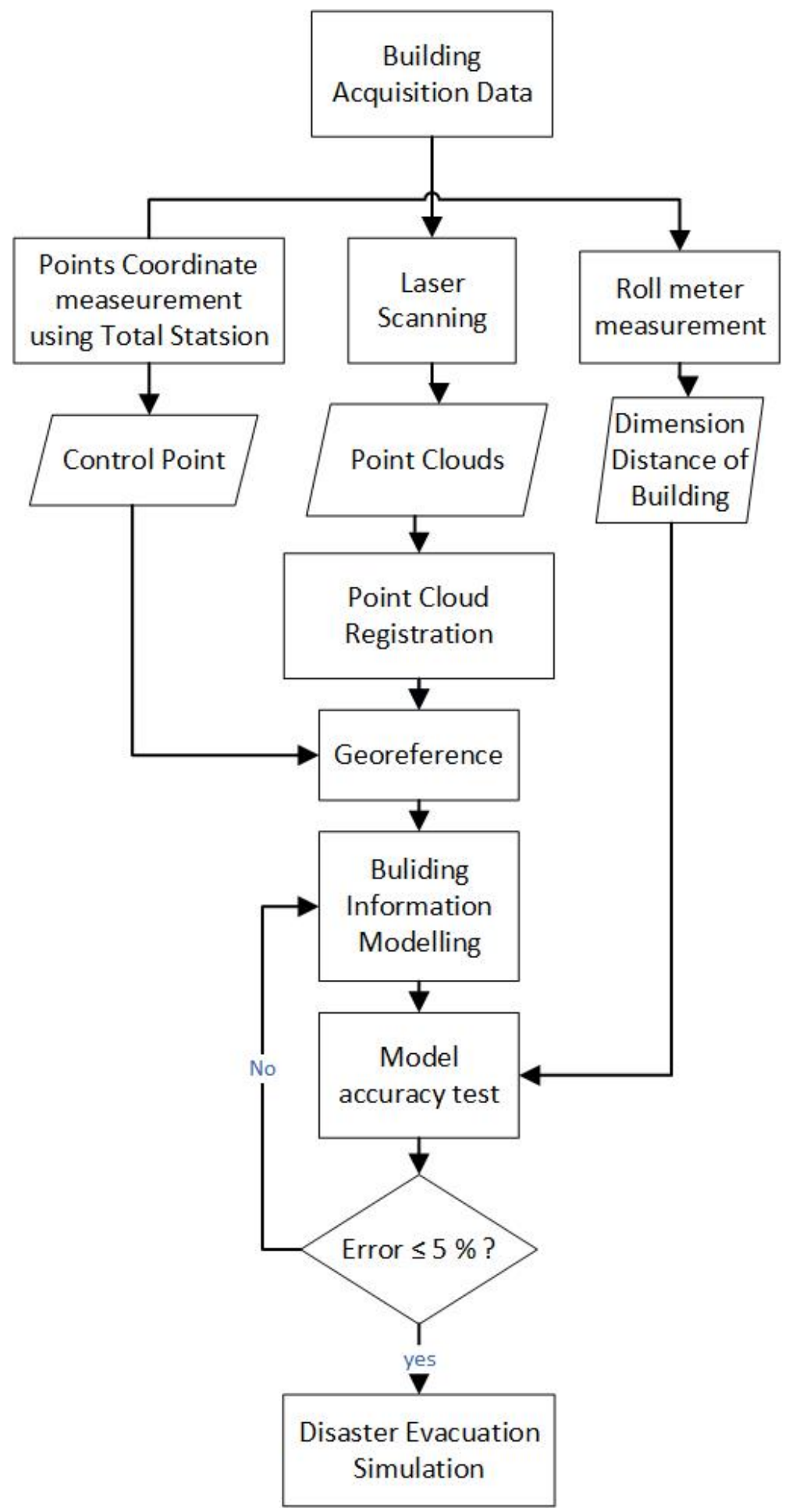

Figure 2. Flowchart of the research

Figure 2 shows how the sequence of studies in this study, in which the Terrestrial Laser Scanning data is pre-processed through registration and georeference to ensure the position and dimensions of the point cloud data. Then the data can be modelled into a Building Information Model (BIM) after fulfilling the RMSE value of the georeference based on the transformation of the control point coordinate data. The results of this modelling are tested geometrically with an error limit of $5 \%$ to be used in making disaster evacuation simulations. The details of each process are described in the following explanation:

\subsubsection{Data Preparation and Acquisition}

The preparation stage consisted of a literature study, field survey, and tool preparation. The literature study was conducted to find and assist researchers in understanding 
the basic concepts related to this research and to explore previous studies related to the material of this research. Meanwhile, a field survey aimed to determine the condition of the object and the environment around the research location. Furthermore, tool preparation was carried out to test the quality, completeness, and condition of the equipment before being used. The tool utilized in this study was TLS BLK360. This tool had been calibrated so that researchers only needed to check the condition of the tool.

Apart from that, the acquisition phase consisted of measuring the Total Station (TS) and Terrestrial Laser Scanner (TLS). The TS measurement was carried out to obtain polygon coordinate data and detail points on the building. The type of polygon in this measurement was a closed polygon. Coordinates of measurement results were used as the Ground Check Point (GCP), Independent Check Point (ICP), and validation of measurement results. In this study, the georeferenced method employed was Indirect Georeference. Meanwhile, the TLS data acquisition was carried out using the Terrestrial Laser Scanner (TLS) BLK360. The TLS measurement aimed to obtain point cloud data at the bottom of the building and the interior of the building.

\subsubsection{Point Cloud Registration}

The point clouds obtained from the TLS measurement had not been merged into one and were still fragmented at their respective local coordinates so that they needed a registration process to combine them.

Registration is a transformation process from a point cloud generated from several scan worlds (SW) to be in the same coordinate system [7]. Similar to aerial photography activities or stereo models, the overlap is required for 3-dimensional object results. The Terrestrial Laser Scanner tool also needs overlap from two adjacent data collection locations [8]. In general, there are several approaches to carrying out the registration process, namely as follows: a) Using a custom target (provided by the scanner manufacturer) that is visible in both point clouds.

b) Using common natural point features.

c) Using surface matching.

d) Using common geometric objects (e.g., shapes, cylinders, etc.).

In this study, the applied point cloud registration approach was the registration using the natural point feature. In this method, the registration is carried out by using natural point features, such as steel edges, building corners, and windows as fastening points. Natural point features must be identified manually in the point cloud by the operator.

\subsubsection{Georeference}

Georeference is important for the integration of TLS data and derivative products, such as 3D models, with other geospatial data. Georeference is a point cloud transformation procedure from a scanner coordinate system to an external, local, or national coordinate system. Applicable approaches to georeference in the TLS in recent years are indirect georeference and direct georeference. In indirect georeference, scans taken from multiple locations must be first combined (registered) into a single point cloud of all objects or sites. After that, the "registered" point cloud is converted into an external coordinate system using the coordinates of at least 3 distributed-control points, which is realized using special targets placed on or around the scanned object. Meanwhile, in direct georeference, the scanner has been integrated with GPS so that the point cloud data already have a coordinate system [7].

In this study, the applied georeferenced method was indirect georeference. In this method, a target with known coordinates in an external system is most often used to convert the point cloud to this system. The relationship between the two systems is described as shown in Figure 3 presenting the case of the two scanning coordinate systems with 6 transformation parameters.

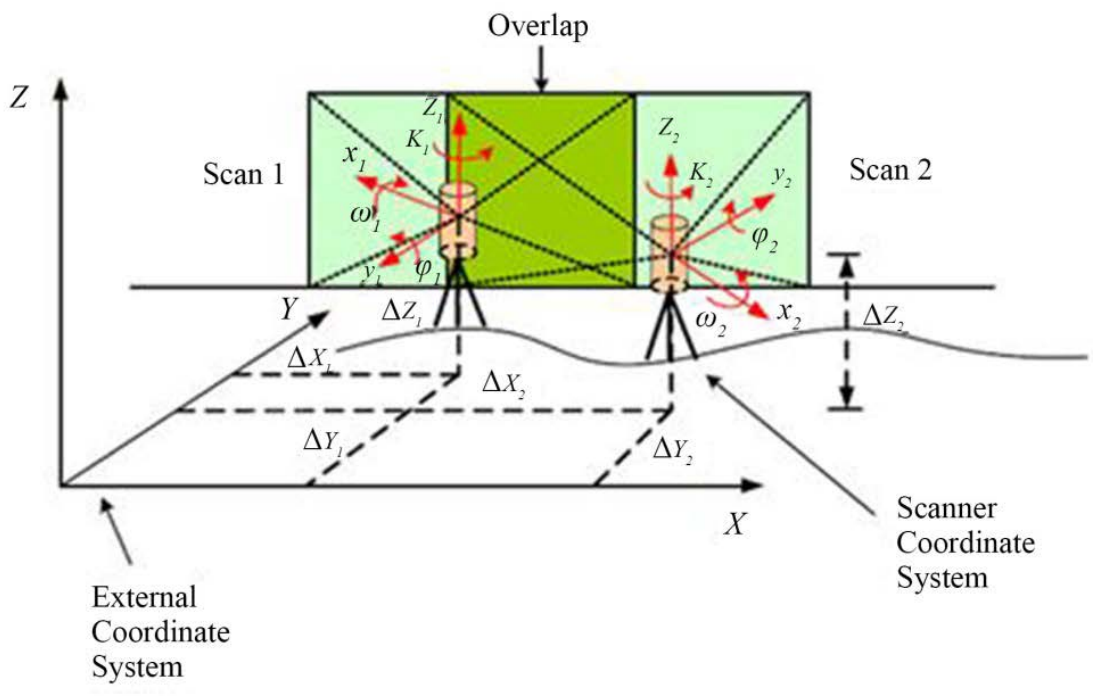

Figure 3. Relationship between scanner coordinate system and external coordinate system 


\subsubsection{Building Information Modelling}

According to the British Standards Institute (ISO 19650), Building Information Model (BIM) is the use of shared digital representations of constructed objects (including buildings, bridges, roads, manufacturing processes, etc.) to facilitate the design, construction, and operation processes to form a reliable basis for decisions. BIM objects are digital representations of products and equipment that can be applied by customers into their building information models. In essence, the BIM makes it easy for all stakeholders in the building life cycle to share information about the building. This allows everyone from architects, surveyors, building engineers, and building owners to use the same shared 3D model. This helps everyone gain access to the right information at the right time throughout the building designing and construction processes.

In this study, the building model or the Building Information Model (BIM) was made using the Autodesk Revit application. Broadly speaking, the process of making $\mathrm{BIM}$ in this study is by digitizing on-screen on point cloud data based on building objects.

\subsubsection{Model Accuracy Test}

The accuracy test on the results of the TLS and BIM was carried out because there was a geometric distortion between the point cloud and objects in the field. Geometric distortion is the imperfection of point geometry contained in point clouds during the registration process or georeference. This causes the size, position, and building to be inconsistent with actual conditions [9]. The magnitude of the error value is indicated by the RMSE (root mean square error). The RMSE is a value of the difference between the actual value and the measured value [10]. The RMSE value is obtained using Equation 1 as follows.

$$
\mathrm{RMSE}=\sqrt{\frac{\sum\left(\mathrm{R}-\mathrm{R}_{1}\right)^{2}}{\mathrm{n}}}
$$

Where:

RMSE: Root Mean Square Error

$\mathrm{R}$ : Value that is considered correct

$\mathrm{R} 1$ : Value of validation measure result

$\mathrm{n}$ : The number of sizes used

\section{Result and Discussion}

\subsection{Results and Analysis of Point Cloud Registration}

The results of merging or registration of TLS point cloud data can be seen in Figure 4.

Figure 4 shows the results of merging or point cloud registration of 260 scanning points. For the display of point cloud, researchers used the intensity mode which is obtained from the laser intensity value on each object. The red parts indicate that the intensity value (the value of the signal return from the laser) is quite low. Meanwhile, the green parts indicate that the laser intensity value is quite high.

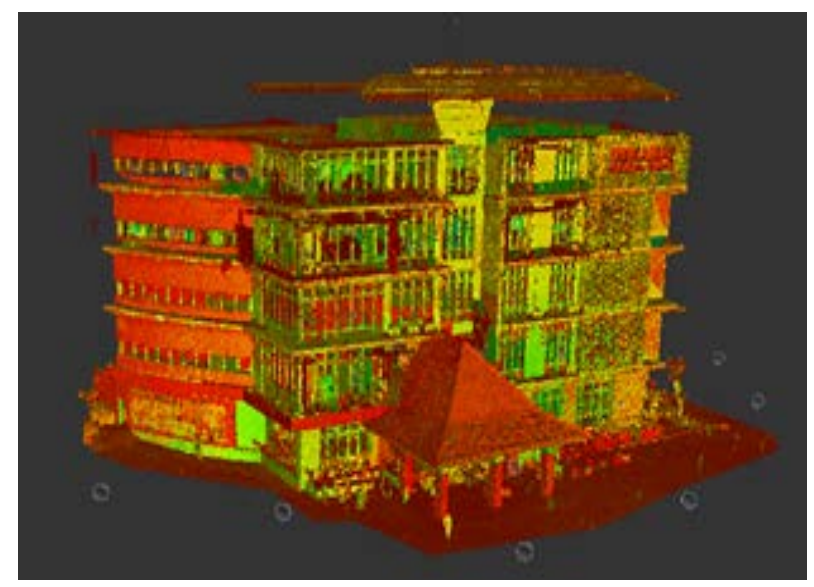

Figure 4. The results of point cloud registration

Overall, the results of point cloud registration in this study are quite good, as seen in Figure 5.

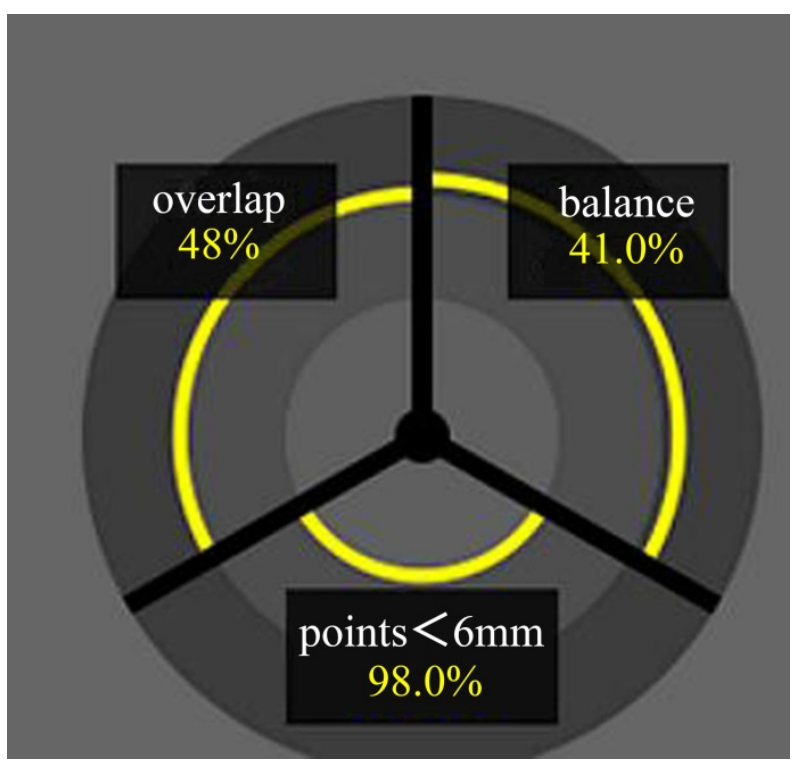

Figure 5. The Report of the TLS registration

These results can be considered to be good because each parameter has met the tolerance level, namely as follows.

a) Overlap $=48 \%$ (having a tolerance level of $>30 \%$ )

b) Balance $=41 \%$ (having a tolerance level of $>20 \%$ )

c) Points $(<6 \mathrm{~mm})=98 \%$ (having a tolerance level of $>$ 90\%)

\subsection{Results and Analysis of the Georeferenced Point Clouds}

The tie points or Ground Check Points (GCP) in this study consisted of 5 points scattered throughout the building. The tools used in measuring GCP are Total Station Reflectors by aiming directly at the building object that will be used as the GCP object, such as the corner of the roof, pillars, or walls. 


\begin{tabular}{|c|c|c|}
\hline target & alignment confidence & RMS (noise) \\
\hline DT039 & $41.64 \mathrm{~mm}$ & $17.47 \mathrm{~mm}$ \\
\hline DTO41 & $61.87 \mathrm{~mm}$ & $15.54 \mathrm{~mm}$ \\
\hline DT027 & $73.10 \mathrm{~mm}$ & $8.41 \mathrm{~mm}$ \\
\hline DT003 & $44.51 \mathrm{~mm}$ & $7.78 \mathrm{~mm}$ \\
\hline PD134 & $60.58 \mathrm{~mm}$ & $2.96 \mathrm{~mm}$ \\
\hline
\end{tabular}

Figure 6. The Report of the TLS Georeference

As seen in the results of the Root Mean Square Error (RMSE) in figure 6, each point has an RMSE value below $2 \mathrm{~cm}$, with the highest value of $1.747 \mathrm{~cm}$, the lowest value of $0.296 \mathrm{~cm}$, and the average value of $1.043 \mathrm{~cm}$. Based on the specifications of the Leica BLK 360, the tool has a point accuracy of about $10 \mathrm{~mm}$. Meanwhile, in this study, the RMSE value was in the range between $2.96 \mathrm{~mm}$ and $17.47 \mathrm{~mm}$. Therefore, the RMSE value in this study can be considered to be sufficient because it has a difference of about $7 \mathrm{~mm}$ with the specifications of the tool previously mentioned.

In this study, the value of Alignment Confidence ranged from $4 \mathrm{~cm}$ to $7 \mathrm{~cm}$, with the highest value of $7.310 \mathrm{~cm}$, the lowest value of $4.164 \mathrm{~cm}$, and the average value of 56.34 $\mathrm{cm}$. In a study conducted by [11], it was explained that the limit of the Alignment Confidence value in the georeferenced process of TLS data is $0.6 \mathrm{~m}$. Therefore, the value of Alignment Confidence in this study can be considered to be quite good.

\subsection{The Results and Analysis of the Creation of BIM}

In this study, the Building Information Model (BIM) was created by digitizing on-screen and utilizing the results of the point cloud. This process was carried out using Autodesk Revit software. The following figure 7 is the result of the creation of the BIM of the New Dean's Building of the Faculty of Engineering, Diponegoro University.

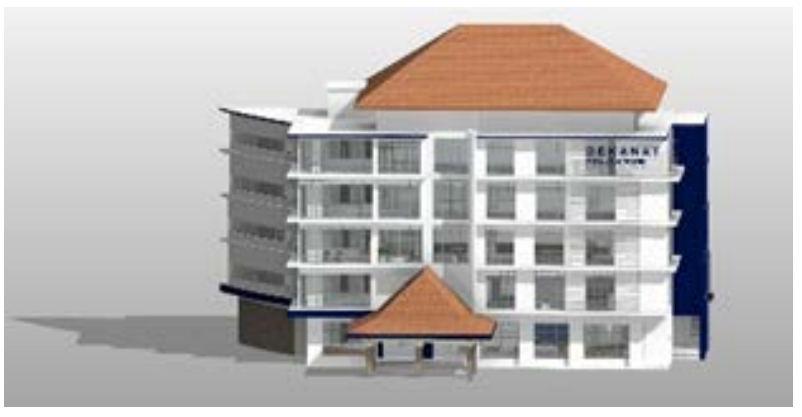

Figure 7. Results of the creation of the BIM

\subsubsection{Analysis of the BIM Visualization}

Visual analysis was carried out to validate the architectural design of the model in terms of accessibility by checking that each space is connected and there are no gaps or isolated spaces. This validation is carried out by comparing the architectural form of the building in the field with the model made [12].

Visual analysis was also carried out using the Level of Detail (LoD) concept approach. The LoD concept was used to show the accuracy of the geometric details of the model, especially buildings. Based on the LoD classification in the article written by [13], the results of this study belonged to the LoD class 3 . In LoD class 3 , not only surface objects, such as walls, floors, and stairs, are depicted, but furniture objects are also depicted although they are still simple objects. It can be seen in Figure 8, in which objects, such as tables, cabinets, and sofas, are well represented.
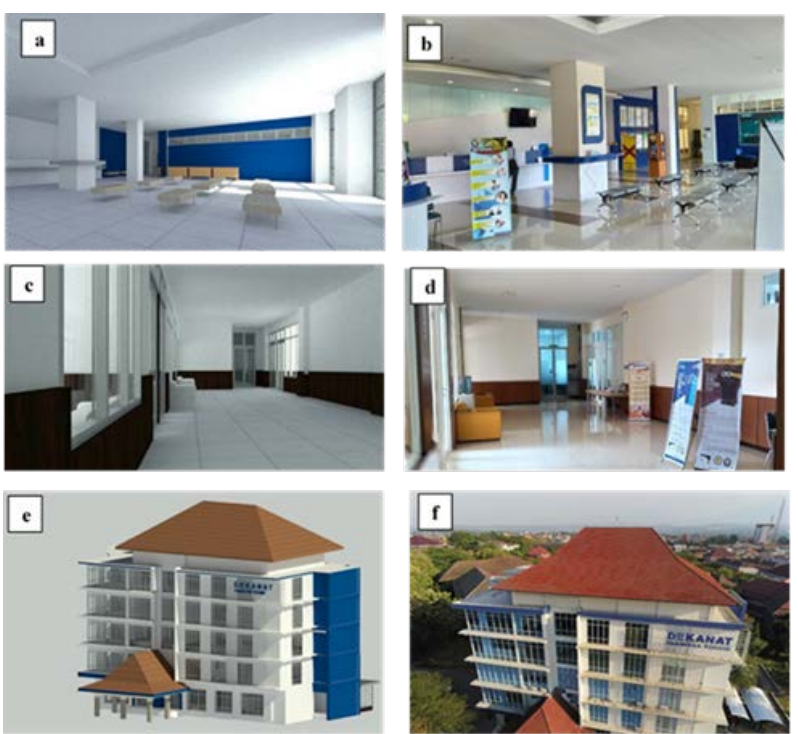

Figure 8. Comparison between the BIM and the architectural form of buildings in the field

\subsubsection{The Analysis of Point Cloud and the Surface of the BIM}

The process of making the BIM was started with collecting point clouds, which were then digitized into building objects. Therefore, it was important to evaluate the deviation of the BIM according to the point cloud. Evaluation of the BIM deviation to the point cloud was carried out gradually on each floor. The results of the deviation evaluation were displayed in the form of gradient maps and diagrams, as seen in Figure 9. 


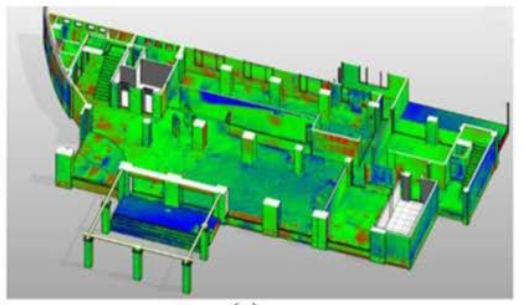

(a)

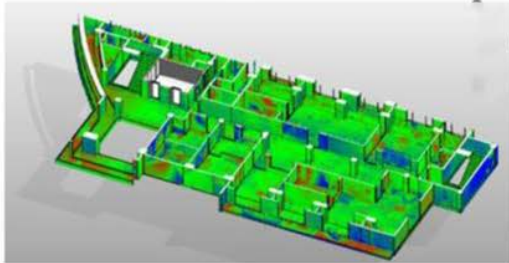

(c)

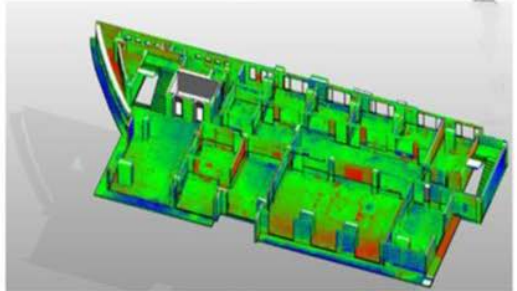

(e)

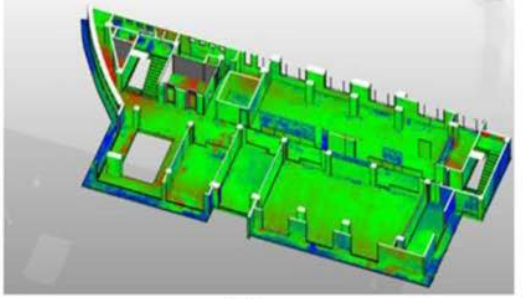

(g)

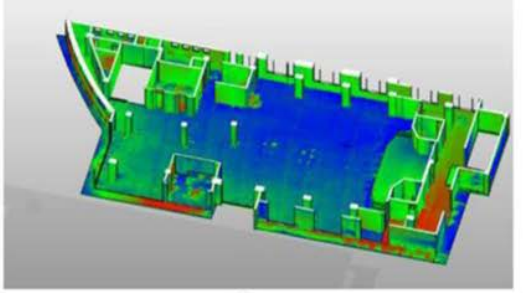

(i)

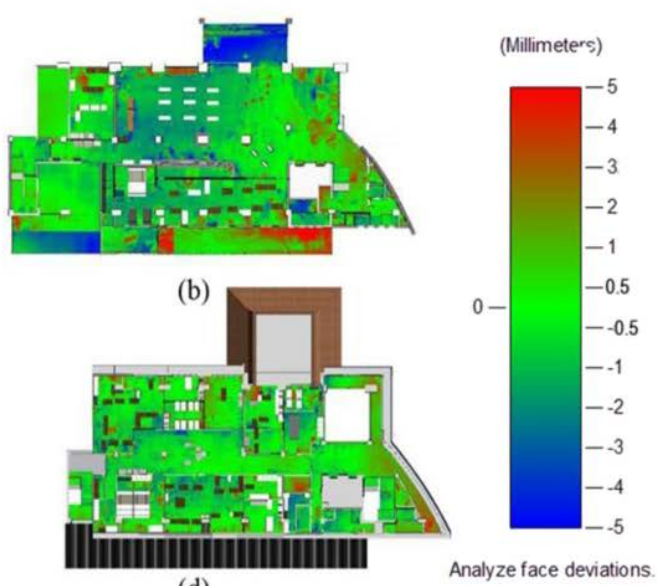

(d)

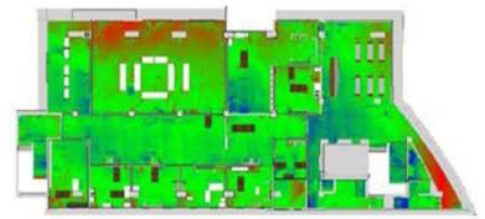

(f)

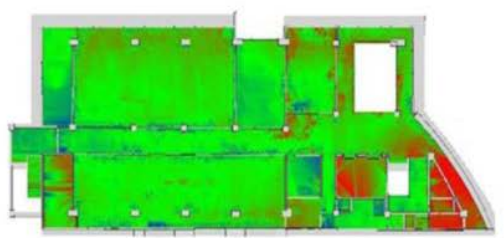

(h)

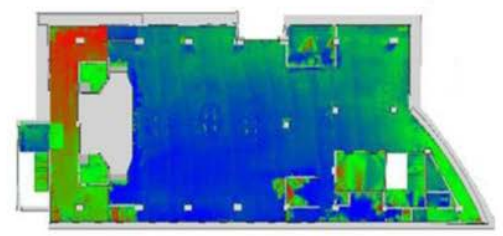

(j)

Figure 9. The results of the deviation of the BIM to point cloud

The results of the deviation evaluation were dominated by the green results. This means that the deviation of the distance between the point cloud and the BIM data ranges from 0 to $2 \mathrm{~mm}$. The red area shows that the deviation of the distance between the point cloud and the BIM is in the range of $+5 \mathrm{~mm}$ because the red area indicates the presence of obstacles, such as tables, piles of cardboard, or chairs. Meanwhile, the blue area shows that the BIM surface is above the point cloud surface in the range of 2 to $5 \mathrm{~mm}$ so that the blue area has a negative value.

When compared with the results of a study conducted by [1], the deviation results in this study are quite good because, in the study conducted by [1], the obtained deviation results ranged from $0 \mathrm{~mm}$ for the lowest value to
$25 \mathrm{~mm}$ for the highest value. Meanwhile, in this study, the deviation ranged from $2 \mathrm{~mm}$ to $5 \mathrm{~mm}$, which was a better value than previous studies

\subsection{The Results and Analysis of the Accuracy Test}

The accuracy test was carried out to determine the level of accuracy of the point cloud and the BIM made. The accuracy test method was conducted by comparing the dimensions of distance in the field, point cloud, and the BIM made. For the measurement of distance dimensions in the field, the researchers used a rolling meter.

In a study conducted by [14], they explained the classification of the quality of size data when comparing 
the length of the interior wall design with the actual length. The following are those classification classes.

a) Good: If the length of the model differs by less than \pm $2 \%$ from the actual length.

b) Acceptable: If the length of the model differs by less than $\pm 5 \%$ but more than $\pm 2 \%$ from the actual length.

c) Unacceptable: If the length of the model differs by more than $\pm 5 \%$ from the actual length.

The results of the calculation of the BIM data quality test can be seen in Table 1.

Table 1. Results of the geometric quality test on the BIM data

\begin{tabular}{|c|c|c|c|c|}
\hline ID & $\begin{array}{c}\text { ROLL } \\
\text { METER } \\
\text { (m) }\end{array}$ & $\begin{array}{c}\text { BIM } \\
\text { (m) }\end{array}$ & $\begin{array}{c}\text { The Difference } \\
\text { between } \\
\text { ROLL } \\
\text { METER \& } \\
\text { BIM (m) } \\
\end{array}$ & Quality \\
\hline \#001 & 1.45 & 1.472 & -0.022 & Good \\
\hline \#003 & 2.115 & 2.126 & -0.011 & Good \\
\hline \#008 & 2.37 & 2.376 & -0.006 & Good \\
\hline \#005 & 0.94 & 0.934 & 0.006 & Good \\
\hline \#012 & 0.64 & 0.645 & -0.005 & Good \\
\hline \#014 & 1.42 & 1.415 & 0.005 & Good \\
\hline \#021 & 1.344 & 1.344 & 0 & Good \\
\hline \#023 & 2.435 & 2.43 & 0.005 & Good \\
\hline \#025 & 2.2 & 2.202 & -0.002 & Good \\
\hline \#034 & 1.83 & 1.814 & 0.016 & Good \\
\hline \#035 & 1.46 & 1.46 & 0 & Good \\
\hline \#036 & 1.44 & 1.45 & -0.01 & Good \\
\hline \#038 & 1.48 & 1.483 & -0.003 & Good \\
\hline \#046 & 1.33 & 1.328 & 0.002 & Good \\
\hline \#057 & 1.805 & 1.811 & -0.006 & Good \\
\hline \#059 & 1.4 & 1.406 & -0.006 & Good \\
\hline \#062 & 2.16 & 2.147 & 0.013 & Good \\
\hline \#064 & 2.37 & 2.358 & 0.012 & Good \\
\hline \#067 & 1.34 & 1.33 & 0.01 & Good \\
\hline \#069 & 1.88 & 1.877 & 0.003 & Good \\
\hline$\# 070$ & 1.4 & 1.368 & 0.032 & Acceptable \\
\hline \#071 & 0.84 & 0.84 & 0 & Good \\
\hline \#072 & 0.545 & 0.578 & -0.033 & Good \\
\hline \#074 & 0.55 & 0.58 & -0.03 & Good \\
\hline \#075 & 1.8 & 1.784 & 0.016 & Good \\
\hline
\end{tabular}

From the data presented in the table above, it can be known as follows. a) The average distance difference between the roll meter and the TLS is $0.008 \mathrm{~m}$

b) The highest distance difference between the roll meter and the TLS is $0.025 \mathrm{~m}$

c) The RMSE value for the difference between the roll meter and the TLS is $0.012 \mathrm{~m}$

d) The average distance difference between the roll meter and the BIM is $0.010 \mathrm{~m}$

e) The highest distance difference between the roll meter and the BIM is $0.032 \mathrm{~m}$

f) The RMSE value for the difference between the roll meter and the BIM is $0.014 \mathrm{~m}$

The average of the result from this measurement indicates good quality. When compared with a study conducted by [15], the result of the test of accuracy in this study is better, as shown as follows.

a) The RMSE value in the study conducted by Alvatara Partogi Hutagalung ranges from $0.0173 \mathrm{~m}$ to 0.0213 $\mathrm{m}$.

b) The RMSE value in this study ranges from $0.0116 \mathrm{~m}$ to $0.0139 \mathrm{~m}$.

It can be seen that the RMSE value in this study is smaller than the previous study. This indicates that the results obtained in this study have fairly better quality.

\subsection{The Results and Analysis of the Disaster Evacuation Path}

The results of making evacuation routes can be directly displayed in the Revit project if the Dynamo application has been integrated with the Revit application. The evacuation route was only made on the 3rd floor of the building. On the 4th floor of the building, the evacuation route was not created because it was an open hall with a small number of rooms.

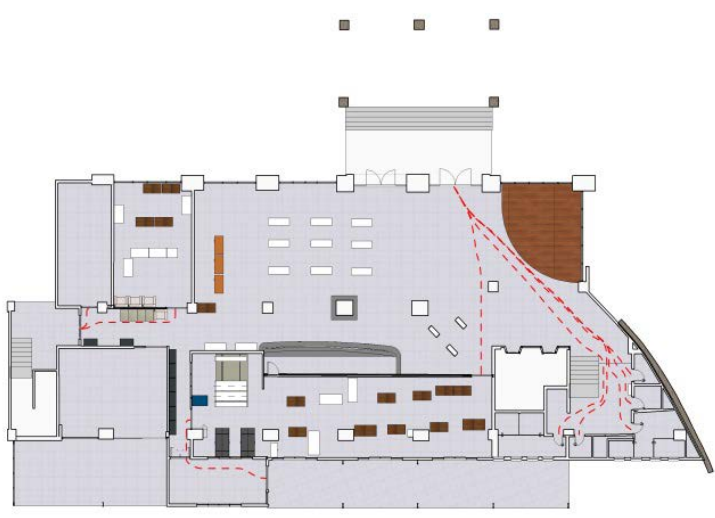

Figure 10. Evacuation routes on the ground floor

The results of the evacuation route on the ground floor can be seen in Figure 10. In this evacuation route, the longest path is $21.251 \mathrm{~m}$, the shortest path is $1.5217 \mathrm{~m}$, and the average length of the path is $14.105 \mathrm{~m}$.

The results of the evacuation route on the first floor can 
be seen in Figure 11. In this evacuation route, the longest path is $17.290 \mathrm{~m}$, the shortest path is $3.009 \mathrm{~m}$, and the average length of the path is $9.514 \mathrm{~m}$.

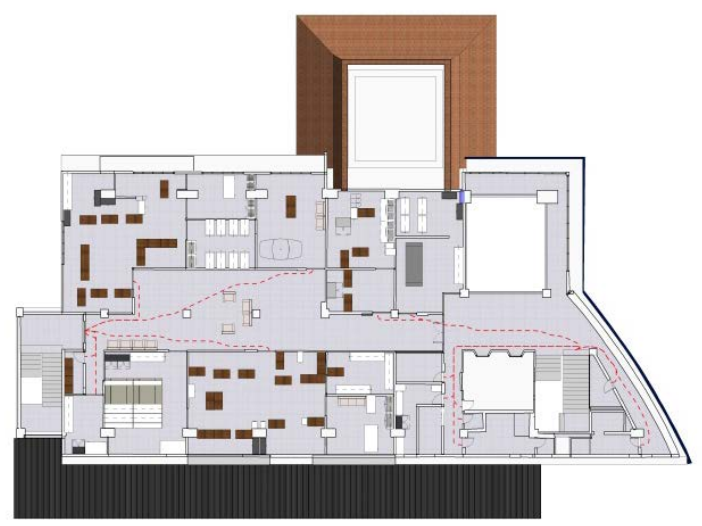

Figure 11. Evacuation routes on the first floor

The results of the evacuation route on the second floor can be seen in Figure 12. In this evacuation route, the longest path is $17.718 \mathrm{~m}$, the shortest path is $2.761 \mathrm{~m}$, and the average length of the path is $10.480 \mathrm{~m}$.

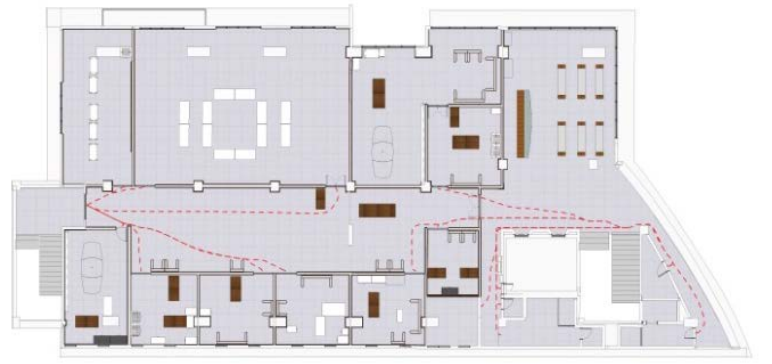

Figure 12. Evacuation routes on the second floor

The results of the evacuation route on the second floor can be seen in Figure 13. In this evacuation route, the longest path is $17.851 \mathrm{~m}$, the shortest path is $2.816 \mathrm{~m}$, and the average length of the path is $11.911 \mathrm{~m}$.

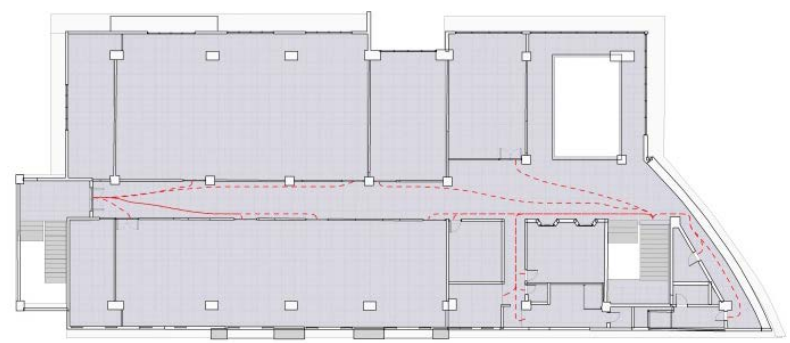

Figure 13. Evacuation routes on the third floor

\subsection{The Results and Analysis of the Disaster Evacuation Simulation}

In this study, a BIM-based fire evacuation simulation was carried out based on point cloud data so that the BIM has represented the actual state of the building. The simulation creation process was carried out using the Pathfinder software.

In this simulation, it is assumed that the condition of the building's evacuation route is in an ideal condition, in which the exit door on the ground floor to the 3rd floor is open. The result can be seen in Figure 14 which is a graph showing the duration of the evacuation process.

The graph shows the number of occupants remaining in the building at any given time. The evacuation process lasted for 104.8 seconds until the last occupant left the building. On average, building occupants can leave the building within 47.2 seconds. The longest route for occupants leaving the building is $64.4 \mathrm{~m}$, while the shortest is $3.9 \mathrm{~m}$. In addition, the average route for each occupant leaving the building is $37.2 \mathrm{~m}$.

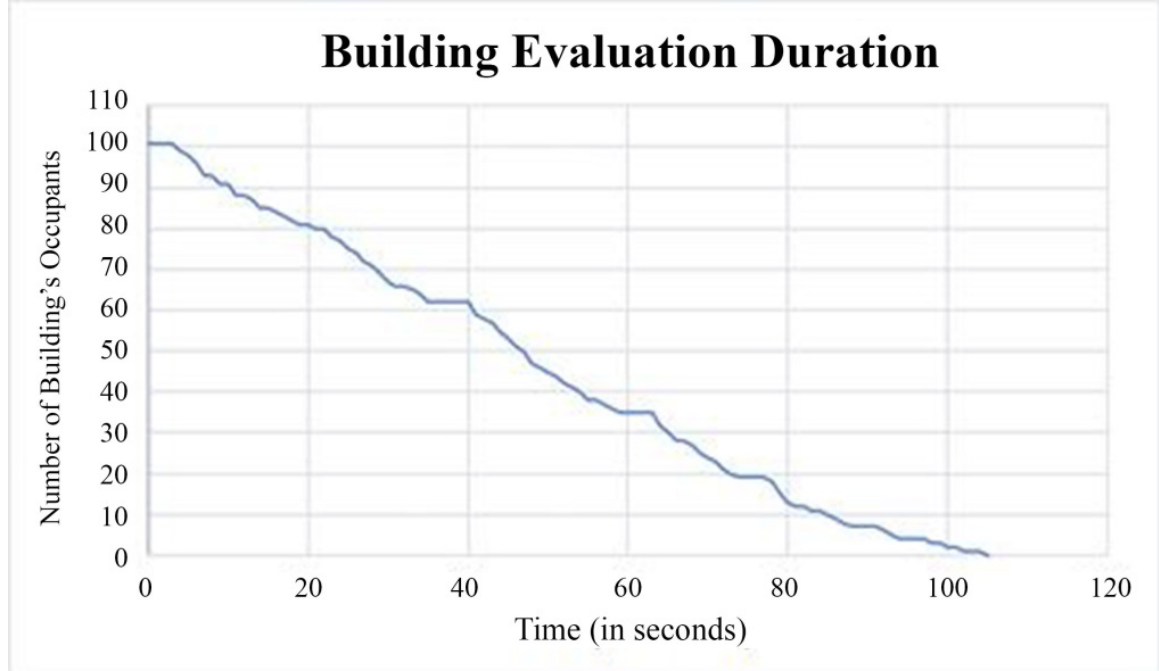

Figure 14. The graph of evacuation duration in the second case 


\section{Conclusions}

Based on the results of this study, it can be concluded as follows:

Visually, the architectural form between the building in the field and the building in the BIM looks the same. However, not all objects in the field are represented in BIM. The objects represented in the BIM are the only objects that are predicted to have an effect on the disaster evacuation process. Based on the LoD classification, this study can be included in LoD class 3. In this class, not only surface objects, such as walls, floors, and stairs, are depicted, but the furniture objects are also described even though they are just simple objects.

The results of the deviation evaluation of the BIM to the average point cloud are dominated by green results. This means that the deviation of the distance between the point cloud and the BIM data ranges from 0 to $2 \mathrm{~mm}$. The red area shows that the deviation of the distance between the point cloud and the BIM is in the range of $+5 \mathrm{~mm}$ because the red area indicates the presence of obstacles, such as tables, piles of cardboard, and chairs. Meanwhile, the blue area shows that the BIM surface is above the point cloud surface in the range of 2 to $5 \mathrm{~mm}$ so that the blue area has a negative value. When referring to the standard specification from USIBD (U.S. Institute of Building Documentation, 2016), this study has a level of accuracy (LOA) ranging from 40 to 50. This level of accuracy indicates that the deviation results in this study have a medium-to-high level of accuracy.

Visually, the results of making evacuation routes are quite good, in which there are no paths that hit walls or obstacles. The maximum distance of the evacuation route in this building is $21.251 \mathrm{~m}$ on the ground floor, $17.290 \mathrm{~m}$ on the 1st floor, $17.718 \mathrm{~m}$ on the 2nd floor, and $17.851 \mathrm{~m}$ on the 3rd floor. The length of the path has been in line with the applicable regulations, in which according to Indonesia's Minister of Public Works and Housing Regulation No. 26/2008, the maximum length of the path in educational residential buildings is $62 \mathrm{~m}$. However, in the New Dean's Building of the Faculty of Engineering, Diponegoro University, 2 areas do not meet the minimum standard for exit access width, in which the tolerance for exit access width is $0.915 \mathrm{~m}$. Meanwhile, in this residential building, there is a corridor with a width of $0.718 \mathrm{~m}$ on the ground floor and a door with a width of $0.732 \mathrm{~m}$ on the 2 nd floor.

\section{Acknowledgements}

We are very grateful to Diponegoro University for funding this research and publication through the World Class University (WCU) Program.

\section{REFERENCES}

[1] M. Bonduel, M. Bassiera, M. Vergauwena, P. Pauwels. Scan-To-Bim Output Validation: Towards A Standardized Geometric Quality Assessment of Building Information Models Based On Point Clouds, International Archives of the Photogrammetry, Remote Sensing and Spatial Information Sciences, Volume XLII-2/W8, 2017. https://doi.org/10.5194/isprs-archives-XLII-2-W8-45-2017

[2] R. Volk, J. Stengel, F. Schultmann. Building Information Modeling (BIM) for existing buildings - Literature review and future needs, Automation in Construction 38, pp. 109127, 2014. https://doi.org/10.1016/j.autcon.2013.10.023

[3] C. Thomson. From Point Cloud to Building Information Model - Capturing and Processing Survey Data Towards Automation for High Quality 3D Models to Aid a BIM Process, University College London (UCL): PhD Thesis, London, 2016. https://doi.org/10.13140/RG.2.2.19058.7136 $6 / 1$

[4] E. B. Anil, P. Tang, B. Akinci, D. Huber. Assessment of Quality of As-is Building Information Models Generated from Point Clouds Using Deviation Analysis, Proc. SPIE 7864, Three-Dimensional Imaging, Interaction, and Measurement, 78640F, 2011. https://doi.org/10.1117/12.876 554

[5] D. Semič. Fire safety analysis of the Crystal Palace based on optimized BIM model, University of Ljubljana: Master Thesis, Ljubljana, 2016. https://repozitorij.uni-lj.si/IzpisGra diva.php?lang=eng\&id $=87975$

[6] L. V. Elswijk. Hierarchical Path-finding Theta *: Combining Hierarchical A * with Theta *, Radboud University: Bachelor Thesis, Nijmegen, 2011.http://www.cs.ru.nl/bache lorscriptieplannen/2011_1_voorjaar/IC_Linus_van_Elswijk. pdf

[7] Y. Reshetyuk. Self-calibration and direct georeferencing in terrestrial, Doctoral thesis in Infrastructure, Royal Institute of Technology, Stockholm, 2009. http://kth.diva-portal.org/s mash/get/diva2:139761/FULLTEXT01.pdf

[8] Y. Prasetyo. State-of-Art Konservasi Bangunan dan Cagar Budaya Melalui Pembentukan Model 3 Dimensi Berbasis Teknik Fortogrametri Rentang Dekat, ELIPSOIDA Vol 01 No 02, 14-20, 2018. https://ejournal2.undip.ac.id/index.php/ elipsoida/article/view/3698

[9] R. W. Priambodo. Studi Ketelitian Planimetrik Pada Model 3d Pengukuran Terrestrial Laser Scanner. Institut Teknologi Sepuluh Nopember: Bachelor Thesis, Surabaya, 2016.

[10] C. D. Ghilani, P. R. Wolf. Adjustment Computations: Spatial Data Analysis. John Wiley dan Sons inc, New York. 2017.

[11] R. A. K. Cox. Real-world comparisons between target-based and targetless point-cloud registration in FARO Scene, Trimble RealWorks and Autodesk Recap. PhD Disertation: University of Southern Queensland, Queensland, 2015. https://eprints.usq.edu.au/29195/1/Cox_R_Zhang.pdf

[12] L. Sanhudo, N. M. Ramos, J. Martins, R. Almeida, E. Barreira, M. Simões, and V. Cardoso. A framework for in-situ geometric data acquisition using laser scanning for BIM modelling. Journal of Building Engineering, 28, 101073, 2020. https://doi.org/10.1016/j.jobe.2019.101073. 
[13] L. Tang, L. Li, S. Ying, Y. Lei. A full level-of-detail specification for 3D building models combining indoor and outdoor scenes. ISPRS International Journal of Geo-Information, 7(11) 419, 2018. https://doi.org/10.3390/ij gi7110419.

[14] F. J. Ariza-López, J. Rodríguez-Avi, J. F. Reinoso-Gordo. I. A. Ariza-López. Quality Control of "As Built” BIM Datasets using the ISO 19157 Framework and a Multiple Hypothesis Testing Method based on Proportions. ISPRS International
Journal of Geo-Information 8(12), 569, 2019. https://doi.org/10.3390/ijgi8120569

[15] A. P. Hutagalung. Y. Prasetyo, B. Sasmito. Analisis Ketelitian Data Pemodelan 3 Dimensi Dengan Metode Traverse Dan Metode Cloud To Cloud Menggunakan Terrestrial Laser Scanner. Jurnal Geodesi Undip, 6(4), 485495, 2017. https://ejournal3.undip.ac.id/index.php/geodesi/a rticle/view/18181 